\title{
Photobiomodulation Decrease Antioxidant Enzymes Activity in Obese Trained Rats
}

Antonio Eduardo de Aquino Junior ${ }^{1 *}$, Fernanda Mansano Carbinatto1, Cynthia Aparecida de Castro ${ }^{1}$, Francine Perri Venturini ${ }^{1}$, Nivaldo Antonio Parizotto ${ }^{2}$ and Vanderlei Salvador Bagnato ${ }^{1}$

São Carlos Institute of Physics, University of São Paulo, PO Box 369, 13560-970, São Carlos, SP, Brazil

\begin{abstract}
It is well established that the use of combined therapies involving exercise and photobiomodulation potentiate the treatment of overweight and obesity and its comorbidities. Nevertheless, the role of antioxidant enzymes in this approach remains to be well understood. The objective of this study was to investigate the effects of exercise combined to Photobiomodulation on the activity of anti-oxidant enzymes. Sixty-four rats were divided in two groups: sedentary and exercised. These groups were fed with normocaloric or high fat diets, and submitted or not to LLLT, totalizing 8 experimental groups. The exercise protocol used was moderate swimming training for 90 min/5 times a week for eight weeks, and LLLT $(830 \mathrm{~nm})$, dose was $4.7 \mathrm{~J} /$ point and the total energy of $9.4 \mathrm{~J}$ per rat. The LLLT application was performed in both gastrocnemius muscles after exercise. The activities of superoxide dismutase (SOD), catalase (CAT) and glutathione peroxidase (GPx) were accessed in muscle by the end of treatments. It was observed a general decrease in these enzymes activities (SOD and CAT) in the LLLT groups, with the exception of an increase in GPx activity in trained animals. The anti-oxidant enzyme showed alterations (Superoxide Dismutase: reduction $\mathrm{SN}$ versus SNL and SN versus SH; Catalase: reduction SN versus SNL, SN versus TN, Sn versus $\mathrm{SH}$, SH versus SHL and SH versus TH; Glutathione Peroxidase: reduction SN versus TN, SH versus TH and increase TH versus THL). All comparisons were significant to $\mathrm{p}<0.05$. We concluded that the combined use of exercise and photobiomodulation promotes modulation of anti-oxidant enzymatic activity.
\end{abstract}

Keywords: Oxidative stress; Physical exercise, Photobiomodulation; Obesity

\section{Introduction}

Obesity is a global epidemic, where $95 \%$ of the cases are of exogenous origin. The main contributing factors are the excessive intake of calories and reduced daily physical activity, increasing in all age groups [1]. Oxidative stress plays an important role in the development of obesity and obesity-associated metabolic disorders [2], like mitochondrial dysfunctions and enzymatic modulations [3].

Among the enzymes directly related to oxidative stress are Superoxide Dismutase (SOD), Catalase (CAT) and Glutathione Peroxidase (GPx). Superoxide Dismutase is an important antioxidant enzyme, responsible for the catalysis of the dismutation of superoxide in oxygen and hydrogen. Catalase is an intracellular enzyme, responsible for the decomposition of hydrogen. And finally, Glutathione Peroxidase, is an enzyme that promotes the detoxification of organic and inorganic peroxides, completing an enzymatic defense system of the cell [4-8].

Thus, the role of Superoxide Dismutase and the other antioxidants enzymes have been extensively studied aiming to unveil the roles of these enzymes in regulation of free radical activity under normal conditions, diseases, exercise and new treatment technologies [4-9].

The obesity, or increased fat accumulation, is one of the most common chronic conditions worldwide and is associated not only with metabolic dysfunction, but also with increased levels of oxidative stress in vivo [10]. Along these lines, peroxidation of unsaturated fatty acids of the cell membrane phospholipids can lead to a significant loss of membrane integrity, which is one of the most striking effects of oxidative damage [11].

To protect against these oxidative deleterious effects, organisms rely on chemical and enzymatic mechanisms [12]. The main antioxidant defense system consists of antioxidant enzymes such as superoxide dismutase (CuZn-Superoxide Dismutase, cytosolic and extracellular-Superoxide Dismutase and Mn-mitochondrial), Catalase (Catalase-heme enzyme) and Glutathione Peroxidase (GR/Glutathione Peroxidase - dependent and not selenium-dependent) to decompose the anion-, $\mathrm{H}_{2} \mathrm{O}_{2}$ and hydroxides [12], besides a non-enzymatic antioxidant system [13].

Some terms have become commonly used in modern discussions of diseases mechanisms, like oxidative stress, antioxidants and free radicals. This last one appears to be a carefully regulated metabolite capable of signaling and communicating important information to the cell's genetic machinery [14]. High levels of free radicals cause damage to cellular components. On the other hand, low to moderate levels of oxidants can regulate roles in cells such as regulation of cell signaling pathways, control of gene expression and modulation of skeletal muscle force production [13].

The antioxidant system works as a complex unit to regulate reactive oxygen species (ROS). In the muscle, these antioxidants are strategically compartmentalized not only in the cytoplasm, but in both extracellular and vascular space, protecting muscle fibers from oxidative injury during periods of increased oxidant production,

*Corresponding author: Antonio Eduardo de Aquino Junior, Ph.D., São Carlos Institute of Physics, University of São Paulo, PO Box 369, 13560 970, São Carlos, São Paulo, Brazil, Tel: 55 (016) 33739810; E-mail: antoniodeaquinojr@gmail.com

Received December 19, 2017; Accepted December 28, 2017; Published December 31, 2017

Citation: Junior AEDA, Carbinatto FM, Castro CAD, Venturini FP, Parizotto NA, et al. (2017) Photobiomodulation Decrease Antioxidant Enzymes Activity in Obese Trained Rats. Bioenergetics 6: 153. doi: 10.4172/2167-7662.1000153

Copyright: (c) 2017 Junior AEDA et al. This is an open-access article distributed under the terms of the Creative Commons Attribution License, which permits unrestricted use, distribution, and reproduction in any medium, provided the original author and source are credited. 
as in intense or prolonged exercise [13]. In order to protect tissues against potential damage caused by ROS, antioxidant enzymes seem to respond adaptively, increasing their activities in the tissues and organs of trained individuals [15].

The activities of anti-oxidant enzymes, like others, are photobiomodulated. Furthermore, little is known about the mechanism of action of laser or LED irradiation on oxidative stress [16]. The objective of this study was to test the hypothesis that the Low Level Laser Therapy (LLLT), associated to aerobic training of moderate intensity, can modulate the antioxidant enzymes activity in obese rats.

\section{Material and Methods}

\section{Animal care}

This ethics committee on animal experimentation approved the experiments under protocol $\mathrm{n}^{\circ}$ 067/2010. The procedures in laboratory were performed according to the Guide for the Care and Use of Laboratory Animals principles. Sixty-four male Wistar rats $(90$ days-old) were kept in individual cages, at a constant temperature of $22 \pm 2{ }^{\circ} \mathrm{C}, 12: 12$ hours light/darkness, fed with standard chow (MP-77; Primor ${ }^{\oplus}$, São Paulo, Brazil) and offered tap water ad libitum.

\section{Experimental groups}

Sixty-four male Wistar rats (90 days old, $317.00 \pm 19.16$ g) were used in this study. Prior to the beginning of the experimental protocol, all groups [except for the normocaloric groups $(\mathrm{N})$ ] were fed ad libitum with the high-fat diet $(\mathrm{H})$ for 3 weeks [1], for the development of obesity and dyslipidemia. The animals were randomized according to diet into eight groups, composed of eight rats each $(n=8)$ : normocaloric diet groups $(\mathrm{N})$ - sedentary normal diet $(\mathrm{SN})$; swimming trained normal diet (TN); sedentary normal diet plus laser (SNL); and swimming trained normal diet plus laser (TNL). High-fat diet groups $(\mathrm{H})$ were divided as sedentary high-fat diet ( $\mathrm{SH})$; swimming trained high-fat diet (TH); sedentary high-fat diet plus laser (SHL), and swimming trained high-fat diet plus laser (THL). Rats were kept one per cage with food and water ad libitum (8 weeks), on a 12:12-h light-dark cycle at $23 \pm$ $1{ }^{\circ} \mathrm{C}$.

\section{Normocaloric diet}

The experimental groups received the normocaloric diet (N)-MP77 standard rat chow diet provided in pellet form (Primor ${ }^{\circledR}$, São Paulo, Brazil), containing $23 \mathrm{~g}$ of protein, $49 \mathrm{~g}$ of carbohydrate, $4 \mathrm{~g}$ of total fat, $5 \mathrm{~g}$ of fiber, $7 \mathrm{~g}$ of ash, and $6 \mathrm{~g}$ of vitamins per $100 \mathrm{~g}$ food.

\section{High-fat diet}

The high-fat diet was comprised by the nor-mocaloric chow diet described above and a surplus of peanuts, milk chocolate, and sweet biscuits, in a proportion of 3:2:2:1. This high-fat diet contained $20 \mathrm{~g}$ of protein, $20 \mathrm{~g}$ of total fat, $48 \mathrm{~g}$ of carbohydrate, and $4 \mathrm{~g}$ of fiber per $100 \mathrm{~g}$ of food. All components of the high-fat diet were ground and blended, and offered to rats in the pellets form.

The caloric density of both diets was determined with an adiabatic calorimeter (IKA-C400), and the values were: $5.12 \mathrm{kcal} / \mathrm{g}$ for the highfat diet and $4.07 \mathrm{kcal} / \mathrm{g}$ for the chow diet [17].

\section{Swimming training}

The swimming training program was conducted as previous described by Aquino Junior [1] (2013), in individual tanks filled with water, maintained at $28-32^{\circ} \mathrm{C}$. The animals of the trained groups swam for 30, 60, and $90 \mathrm{~min}$ on the first, second, and third days to adapt. The swimming period was then increased to $90 \mathrm{~min} /$ day, during 5 days/ week. All rats swam with a load of 3-5\% of the body mass attached to the body by a jacket. The exercise protocols were performed for 5 days/ week during 8 weeks. This program is considered to be of moderate intensity [1].

\section{Photobiomodulation protocols}

The photobiomodulation parameters are shown in Table 1. Light was irradiated transcutaneously on the muscles of the rat's paw (one point on quadriceps and other point on gastrocnemius). The laser was applied after the exercises, using the stress induced by the physical activity to get the maximum of absorption and effects on metabolism. The same protocol was tested and used in earlier studies performed by our research group [18].

\section{Euthanasia, serum and muscle tissue collection}

All animals were euthanized by decapitation at the end of 8 weeks of training, after a 24 -h rest period. The gastrocnemius muscles (GAST) were removed, weighted, and frozen at $-20^{\circ} \mathrm{C}$.

\section{Anti-oxidant assay}

Superoxide dismutase assay (Total-SOD): The assays for TotalSOD were performed by Cayman's assay kit (no. 706002). For TotalSOD, $50 \mu \mathrm{g}$ of muscle were homogenized in $500 \mu \mathrm{l}$ of cold $20 \mathrm{mM}$ HEPES buffer, $\mathrm{pH}$ 7.2, containing $1 \mathrm{mM}$ EGTA, $210 \mathrm{mM}$ mannitol, and $70 \mathrm{mM}$ sucrose per gram tissue. The assay was performed utilizing a tetrazolium salt for detection of superoxide radicals generated by xanthine oxidase and hypoxanthine. The absorbance was read at 440 nm on plate reader [19].

Catalase assay (CAT): The assays were performed by Cayman's assay kit (no. 707002). For the assay, $50 \mu \mathrm{g}$ of muscle were homogenized in $500 \mu \mathrm{l}$ of cold buffer on ice ( $50 \mathrm{mM}$ potassium phosphate, $\mathrm{pH} 7.0$, containing $1 \mathrm{mM}$ EDTA). The method is based on the reaction of the enzyme with methanol in the presence of an optimal concentration of $\mathrm{H}_{2} \mathrm{O}_{2}$. The formaldehyde produced is measured colorimetrically with 4-amino-3-hydrazino-5-mercapto-1,2,4-triazole (Purpald) as the chromogen. The absorbance was read at $540 \mathrm{~nm}$ on plate reader [20].

Glutathione peroxidse (GPx): For assay of the activity of GPx, $50 \mathrm{mg}$ portion of the muscle was homogenized in $500 \mu \mathrm{l}$ of potassium phosphate buffer $(0.1 \mathrm{M} \mathrm{pH} 7.0$ containing $0.25 \mathrm{M}$ sucrose in proportion 1:1). The samples were homogenized on ice, using a teflon pestle rotating at low speed. Subsequently, they were centrifuged for $10 \mathrm{~min}$ at $15,000 \times \mathrm{g}$ at $4^{\circ} \mathrm{C}$. The supernatant was used as source of enzyme. Glutathione peroxidase activity was determined by the method of Beutler [21] (1985), by reacting glutathione reductase and $\mathrm{NADPH}$ oxidation using hydroperoxide as substrate. The decrease in optical density was determined against a blank at $340 \mathrm{~nm}$. The value of the molar extinction coefficient used was $6.20(\mathrm{mM} . \mathrm{cm})^{-1}$.

\section{Protein determination for specific enzymatic activity}

\begin{tabular}{|c|c|c|c|}
\hline Type & Ga-Al-As & Energy density & $\mathbf{1 . 6 6 ~ J / \mathbf { c m } ^ { 2 }}$ \\
\hline Wavelength & $830 \mathrm{~nm}$ (infrared) & Treatment time & $47 \mathrm{~s}$ \\
\hline Frequency & Continuous wave (CW) & Total energy delivered & $9.4 \mathrm{~J}$ \\
\hline Optical output & $100 \mathrm{~mW}$ & Power density & $35.36 \mathrm{~W} / \mathrm{cm}^{2}$ \\
\hline Spot diameter & $0.6 \mathrm{~mm}$ & Energy per point & $4.7 \mathrm{~J} /$ point \\
\hline
\end{tabular}

Table 1: Photobiomodulation parameters. 
A

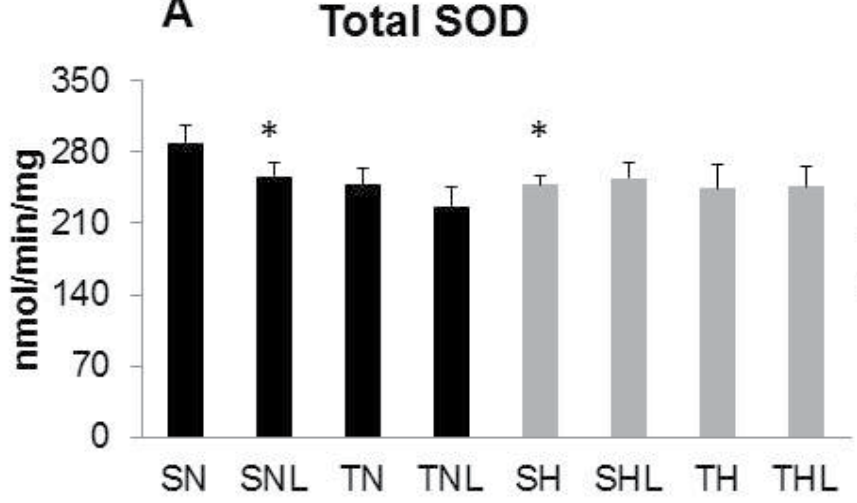

B

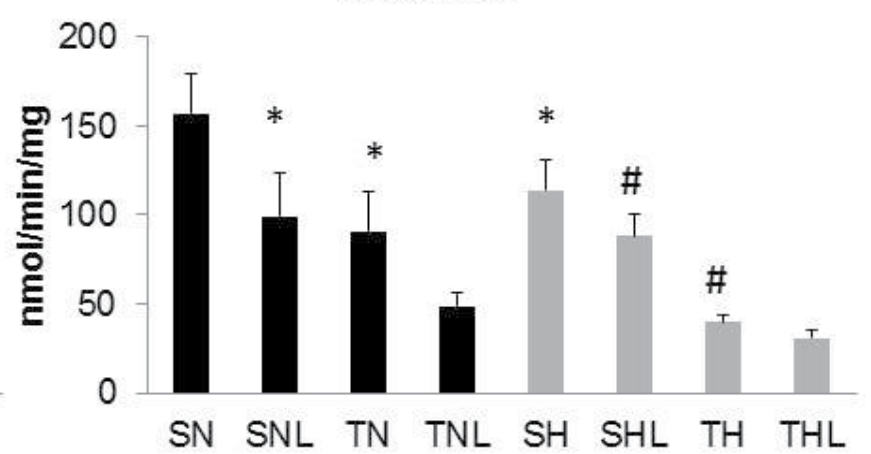

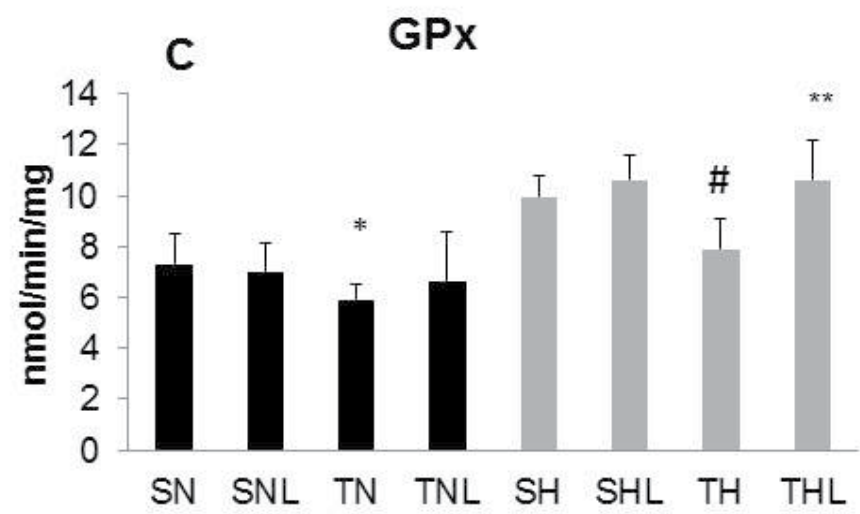

Figure 1: Biochemical assays of antioxidant enzymes activity. Total superoxide dismutase (Total-SOD); catalase (CAT); Glutathione peroxidase (GPx). Data are expressed as mean \pm SD. Sedentary normal diet (SN); Swimming trained normal diet (TN); Sedentary normal diet plus laser (SNL); Swimming trained normal diet plus laser (TNL); Sedentary high-fat diet (SH);Swimming trained high-fat diet (TH); Sedentary high-fat diet plus laser (SHL); Trained high-fat diet plus laser (THL). The letter superscript represents the comparison between groups: * $\mathrm{SN} v \mathrm{SNL} / \mathrm{SN} v \mathrm{TN} / \mathrm{SN} v \mathrm{SH}$; \# SH $v \mathrm{SHL} / \mathrm{SH} v \mathrm{TH}$; +TN $v$ TH / TN $v$ TNL; **TH $v$ THL represented statistical difference $(p<0.05)$.

Protein concentration was determined using the method described by Bradford (1976) with bovine serum albumin (BSA) (Sigma) as standard [22].

\section{Statistical analysis}

The data were expressed as a mean \pm standard deviation. The normality test used was Kolmogorov-Smirnov. For statistical evaluation of the antioxidant enzymes, a one-way ANOVA test with post hoc analysis (Tukey-Kramer multiple comparisons) was used between groups. Statistical analysis were performed using Instat 3.0 for Windows. Statistical significance was set at $\mathrm{p}<0.05$ levels.

\section{Results}

In our study we observed that the sedentary groups, even normal submitted to photobiomodulation (SNL) and sedentary obese group (SH), showed lower values for Total-SOD activity when compared with normal sedentary group ( $\mathrm{SN})(\mathrm{p}>0.05 ; \mathrm{p}>0.01$ respectively) (Figure $1 \mathrm{~A})$. There was no significant changes in the values of specific TotalSOD enzymatic activity for the other groups.

We observed that CAT activity (Figure 1B) was lower at SNL, SH and $\mathrm{TN}(\mathrm{p}>0.001)$ groups compared with SN group. In the SHL group, the photobiomodulation decreased CAT activity when compared with $\mathrm{SH}$ group ( $\mathrm{p}>0.05)$. The obese group, submitted to aerobic training
(TH), presented lower values when compared with $\mathrm{SH}(\mathrm{p}>0.001)$.

The aerobic training in normal group (TN) decreased the GPx activity (Figure 1C) compared with SN group $(p>0.01)$. Aerobic training was also able to decrease GPx activity $(\mathrm{p}>0.05)$ in obese animals $(\mathrm{TH})$ compared with sedentary obese $(\mathrm{SH})$. On the other hand, the association of photobiomodulation with aerobic training, in obese animals, increased the GPx activity of the THL group $(\mathrm{p}>0.01)$ compared with obese trained animals $(\mathrm{TH})$.

\section{Discussion}

In the present study, we analyzed the efficiency of association between the moderate-intensity exercise and the photobiomodulation in modulation of anti-oxidant enzyme activity, in normal and obese trained rats. In our previous study, we found the obesity condition in experimental study, where serum lipids, several fat depots and fat liver showed increased [1]. This condition can lead to increased accumulation of lipids and consequently diseases like type 2 diabetes and cardiac alterations [23].

This modulation of the immune response may be related to lower oxidative damage [24]. Along these lines, it is suggested that biochemical modulation after application of photobiomodulation is attributable to reduction in the extent of inflammatory responses and consequent reduction in ROS generation, result of possible modulation 
of molecular oxygen. In order to verify this association, we evaluated the antioxidant enzymes SOD, CAT and GPx activities.

Concerning the anti-oxidant enzymes activity on gastrocnemius muscle, we observed that the photobiomodulation decreased the TotalSOD in sedentary normal animals. The obese sedentary group showed lesser activity of Total-SOD compared with sedentary normal group. Previous studies showed controversial results about the SOD activity. Some authors observed that chronic endurance training was not able to increase the SOD activity $[25,26]$. On the other hand, other studies have shown opposite results indicating increased activity of SOD in muscles of rats [27-29]. It is noteworthy that the variance of the type of training, fiber type, duration of exercise protocols and study design could explain the different results. However, the photobiomodulation can modulate SOD activity, generating increase [30] or promoting a reduction [31]. Studies show that this reduction in SOD activity is probably due to a reduction in the concentration of superoxide anion [31,32], which can directly modulate the respiratory chain and consequent increase of ATP production. According to Tafur, Mills [33] minimal changes in the levels of ATP can cause changes in cellular metabolism.

Photobiomodulation and swimming training lead to decreases in CAT activity (Figure 1B). However, the association of both interventions did not show significant difference of CAT activity (Figure 1B) in normal animals. In the sedentary obese group, the CAT activity decrease occurred compared with normal sedentary group. Both interventions isolated showed decrease of CAT activity in obese groups. This enzyme is more expressed when in high oxidative muscular fiber than in low oxidative muscular fiber [9]. The studies with the CAT activity are still controversial, but this enzyme can be modulated by exercise and the photobiomodulation. Previous studies report that the exercise [34,35] and photobiomodulation [36] can increase the CAT activity. However, other studies found different results: decreases in CAT activity due to exercise [9,26,37] or no changes at all [38]. It is possible that biochemical modulation occurs due to a decrease in the inflammatory response and consequently a reduction of ROS. Another important factor in ambiguity of these findings may be due to factors with assay CAT activity, thus it is possible that failure in assay standardization is occurring [14].

In a previous study [39] about the GPx (Figure 1C) activity in normal animals, the author observed that in swimming training this activity was higher when compared with sedentary group. In normal animals, both submitted to swimming training and association of swimming training with photobiomodulation, there was a increase the GPx activity. In the obese condition, the swimming training and the association of both interventions increased the GPx activity. Previous studies reported the same results when endurance training was studied in rats [29-39]. In relation to the duration of exercise, we found that the long-duration exercise training sessions, superior to $60 \mathrm{~min} /$ day, is more able to increase muscle activity GPx than short-duration as 30 min/day [14]. We highlight that the GPx activity in our study could be predominant in fiber type I (oxidative metabolism) of gastrocnemius, more actively recruited during submaximal endurance exercise [40]. Similarly to exercise, the photobiomodulation induced modulation in GPx in skeletal muscle, corroborating other studies [41]. Considering that GPx is more effective at low concentrations of ER [42] it is possible that $\mathrm{GPx}$ has dismuted $\mathrm{H}_{2} \mathrm{O}_{2}$, formed by $\mathrm{SOD}$, preventing oxidative damage, once CAT showed reduction.

The applications of exercise and photobiomodulation are now widespread for population. Nevertheless, the underlying mechanisms involved are not fully understood. ROS are considered the key secondary messengers produced by photobiomodulation [42], showing evidence that a change in cellular redox state has been suggested to lead to photo stimulatory processes [43]. The divergence of studies can be in function of dose, duration and energy density used in photobiomodulation.

\section{Conclusion}

The study showed a modulation of enzymatic activity of the antioxidant enzymes studied, in part by the action of obesity induced and in part by chronic exercise conjugated to effect of Photobiomodulation. Our results are the beginning of a new research field that associates antioxidant metabolism roles in the physical exercise and photobiomodulation, bringing new insights for obesity treatment.

\section{Acknowledgement}

The authors acknowledge the support provided by Brazilian Funding Agencies: São Paulo Research Foundation (FAPESP) grants: 2013/07276-1 (CEPOF).

\section{References}

1. Aquino AE Jr, Sene-Fiorese M, Paolillo FR, Duarte FO, Oishi JC, et al. (2013) Low-level laser therapy (LLLT) combined with swimming training improved the lipid profile in rats fed with high-fat diet. Lasers Med Sci 28: 1271-1280.

2. Liu Y, Qi W, Richardson A, Van Remmen, Ikeno Y, et al. (2013) Oxidative damage asssociated with obesity is prevented by overexpression of $\mathrm{CuZn-} \mathrm{or} \mathrm{Mn}$ superoxide dismutase. Biochemical and Biophysical researh Communications 438: 78-83.

3. Cui R, Gao M, Liu D, Qu S (2014) Overexpression of superoxide dismutase 3 gene blocks high fat diet-induced obesity, fatty liver and insulin resistance. Gene Ther 21: 840-848.

4. Kanter MM, Hamlin RL, Unverferth DV, Davis HW, Merola AJ (1985) Effect of exercise training on antioxidant enzymes and cardiotoxicity of doxorubicin. J Appl Physiol 59: 1298-1303.

5. Jenkins RR, Friedland R, Howald H (1984) The relationship of oxygen uptake to superoxide dismutase and catalase activity in human skeletal muscle. Int $J$ Sports Med 5: 11-14.

6. Higuchi M, Cartier LJ, Chen M, Holloszy JO (1985) Superoxide dismutase and catalase in skeletal muscle: adaptive response to exercise. J Gerontol 40: 281-286.

7. Alessio HM, Goldfarb AH, Cutler RG (1988) MDA content increases in fast- and slow-twitch skeletal muscle with intensity of exercise in a rat. Am J Physiol 255 C874-C877.

8. Muthusamy VR, Kannan S, Sadhaasivam K, Gounder SS, Davidson CJ, et al. (2012) Acute exercise stress activates Nrf2/ARE signaling and promotes antioxidant mechanisms in the myocardium. Free Radic Biol Med 52: 366-376.

9. Powers SK, Criswell D, Lawler J, Ji LL, Martin D, et al. (1994) Influence of exercise and fiber type on antioxidant enzyme activity in rat skeletal muscle. Am J Physiol 266: R375-R380.

10. Salmon AB (2016) Beyond Diabetes: does obesity induced oxidative stress drive the aging process? Antioxidants 5: 1-14.

11. Tappel AL (1973) Lipid peroxidation damage to cell components. Fed Proc 32 1870-1874.

12. Yu BP (1994) Cellular defenses against damage from reactive oxygen species Physiol Rev 74: 139-162

13. Powers SK, Jackson MJ (2008) Exercise-induced oxidative stress: cellular mechanisms and impact on muscle force production. Physiol Rev 88: 1243 1276.

14. Dröge W (2002) Free radicals in the physiological control of cell function Physiol Rev 82: 47-95

15. Reddy Avula CP, Fernandes G (1999) Modulation of antioxidant enzymes and lipid peroxidation in salivary gland and other tissues in mice by moderate treadmill exercise. Aging (Milano) 11: 246-252.

16. Montoro LA, Turrioni AP, Basso FG, de Souza Costa CA, Hebling J (2014) Infrared LED irradiation photobiomodulation of oxidative stress in human dental pulp cells. Int Endod J 47: 747-755. 
Citation: Junior AEDA, Carbinatto FM, Castro CAD, Venturini FP, Parizotto NA, et al. (2017) Photobiomodulation Decrease Antioxidant Enzymes Activity in Obese Trained Rats. Bioenergetics 6: 153. doi: 10.4172/2167-7662.1000153

17. Speretta GF, Rosante MC, Duarte FO (2012) The effects of exercise modalities on adiposity in obese rats. Clinics (Sao Paulo) 67: 1469-1477.

18. Vieira WH, Ferraresi C, Perez SE, Baldissera V, Parizotto NA (2012) Effects of low-level laser therapy ( $808 \mathrm{~nm}$ ) on isokinetic muscle performance of young women submitted to endurance training: a randomized controlled clinical trial. Lasers Med Sci 27: 497-504.

19. Marklund S (1980) Distribution of CuZn superoxide dismutase and $\mathrm{Mn}$ superoxide dismutase in human tissues and extracellular fluids. Acta Physio Scand Suppl 492: 19-23.

20. Johansson LH, Borg LA (1988) A spectrophotometric method for determination of catalase activity in small tissue samples. Anal Biochem 174: 331-336.

21. Beutler E (1985) How do red cell enzymes age? A new perspective. $\mathrm{Br} J$ Haematol 61: 377-384.

22. Bradford MM (1976) A rapid and sensitive method for the quantitation of microgram quantities of protein utilizing the principle of protein-dye binding. Anal Biochem 72: 248-254

23. Fain JN (2006) Release of interleukins and other inflammatory cytokines by human adipose tissue is enhanced in obesity and primarily due to the nonfat cells. Vitam Horm 74: 443-477.

24. Silveira PC, Silva LA, Freitas TP, Latini A, Pinho RA (2011) Effects of low-power laser irradiation (LPLI) at different wavelengths and doses on oxidative stress and fibrogenesis parameters in an animal model of wound healing. Lasers Med Sci 26: 125-131.

25. Lambertucci RH, Levada-Pires AC, Rossoni LV, Curi R, Pithon-Curi TC (2007) Effects of aerobic exercise training on antioxidant enzyme activities and mRNA levels in soleus muscle from young and aged rats. Mech Ageing Dev128: 267275 .

26. Laughlin MH, Simpson T, Sexton WL, Brown OR, Smith JK, et al. (1990) Skeletal muscle oxidative capacity, antioxidant enzymes, and exercise training. J Appl Physiol 68: 2337-2343

27. Vincent HK, Powers SK, Stewart DJ, Demirel HA, Shanely RA, Naito H (2000) Short-term exercise training improves diaphragm antioxidant capacity and endurance. Eur J Appl Physio 81: 67-74

28. Vincent HK, Powers SK, Demirel HA, Coombes JS, Naito H (1999) Exercise training protects against contraction-induced lipid peroxidation in the diaphragm. Eur J Appl Physiol Occup Physiol 79: 268-273.

29. Venditti P, Di Meo S (1997) Effect of training on antioxidant capacity, tissue damage, and endurance of adult male rats. Int J Sports Med 18: 497-502.
30. Liu XG, Zhou YJ, Liu TC, Yuan JQ (2009) Effects of low-level laser irradiation on rat skeletal muscle injury after eccentric exercise. Photomed Laser Surg 27: 863-869.

31. Silveira PC, da Silva LA, Pinho CA (2013) Effects of low-level laser therapy (GaAs) in an animal model of muscular damage induced by trauma. Lasers Med Sci 28: 431-436.

32. Servetto N, Cremonezzi D, Simes JC (2010) Evaluation of inflammatory biomarkers associated with oxidative stress and histological assessment of low-level laser therapy in experimental myopathy. Lasers Surg Med 42: 577-583.

33. Tafur J, Mills PJ (2008) Low-intensity light therapy: exploring the role of redox mechanisms. Photomed Laser Surg 26: 323-328.

34. Quintanilha AT (1984) Effects of physical exercise and/or vitamin E on tissue oxidative metabolism. Biochem Soc Trans 12: 403-404.

35. Mohammedi K, Patente TA, Bellili-Muñoz N, Driss F, Monteiro MB, et al. (2013) Catalase activity, allelic variations in the catalase gene and risk of kidney complications in patients with type 1 diabetes. Diabetologia 56: 2733-42.

36. Silveira PC, Silva LA, Fraga DB, Freitas TP, Streck EL, et al. (2009) Evaluation of mitochondrial respiratory chain activity in muscle healing by low-level lase therapy. J Photochem Photobiol B 95: 89-92.

37. Leeuwenburgh C, Fiebig R, Chandwaney R, Ji LL (1994) Aging and exercise training in skeletal muscle: responses of glutathione and antioxidant enzyme systems. Am J Physiol 267: R439-R445.

38. De Marchi T, Leal Junior EC, Bortoli C, Tomazoni SS, Lopes-Martins RA, et al. (2012) Low-level laser therapy (LLLT) in human progressive-intensity running effects on exercise performance, skeletal muscle status, and oxidative stress. Lasers Med Sci 27: 231-236.

39. Venditti P, Di Meo S (1996) Antioxidants, tissue damage, and endurance in trained and untrained young male rats. Arch Biochem Biophys 331: 63-68.

40. Sale DG (1987) Influence of exercise and training on motor unit activation. Exerc Sport Sci Rev 15: 95-151.

41. de Lima FM, Albertini R, Dantas Y, Maia-Filho AL, Santana Cde L, et al. (2013) Low-level laser therapy restores the oxidative stress balance in acute lung injury induced by gut ischemia and reperfusion. Photochem Photobiol 89: 179-188.

42. Subudhi AW, Davis SL, Kipp RW, Askew EW (2001) Antioxidant status and oxidative stress in elite alpine ski racers. Int J Sport Nutr Exerc Metab 11: 32-41.

43. Fujimaki Y, Shimoyama T, Liu Q, Umeda T, Nakaji S, et al. (2003) Low-leve laser irradiation attenuates production of reactive oxygen species by human neutrophils. J Clin Laser Med Surg 21: 165-170. 